\title{
The Scholarship of Canadian Research University Librarians
}

David Fox

Bibliographic Services Librarian

University of Saskatchewan Library

\section{Abstract}

This paper reports the results of a national survey of Canadian research university librarians conducted by the author in 2006. The study deals with the motivation of librarians to engage in scholarly activities, the requirement for scholarship by librarians at Canadian research universities, the perceived importance of scholarship as a criterion for promotion and tenure, levels and forms of participation in scholarship, and librarians' assessment of various types of support for scholarship. The study concluded that $13 \%$ of the sample population could be considered active scholars, and suggests that there may be a correlation between level of scholarly intensity and gender. The paper concludes with questions for further study.

Keywords: Scholarship, scholarly activity, research, Canadian research university librarians, Canadian Association of Research Libraries, CARL

\section{Introduction}

In a survey of 690 U.S. universities, Mitchell and Reichel (232) determined that the vast majority of research, doctoral, and masters-level institutions either required or encouraged some degree of scholarship by tenure track librarians. While there have been numerous studies of the scholarship of university librarians in the United States, little is known of the nature and extent of the scholarly activities of Canadian university librarians.

Librarianship has traditionally been a practice-oriented profession. Most university librarians have significant year-round schedules of assigned duties that present challenges to the engagement in sustained, meaningful scholarship. Furthermore, the present study has demonstrated that there are no commonly agreed upon norms for librarians' time commitment to scholarship. ${ }^{1}$ However, the establishment of such norms clearly has implications for librarians' workloads, for appropriate librarian staffing levels, and consequently for library and university budgets.

\footnotetext{
${ }^{1}$ See Table 1.
} 
What motivates practicing Canadian research university librarians to engage in scholarly activities? In what forms of scholarship do they participate? What are the expectations for scholarly work by librarians in Canadian research universities? What degree of institutional support do Canadian research universities provide for librarians?

This study attempts to document the scholarly activities of Canadian research university librarians. The study also investigates the perceived importance of scholarship in the criteria for promotion and tenure for librarians at Canadian research universities. It seeks information on the level of support for librarians to engage in scholarly pursuits, including time for scholarship, and funding for research and travel.

\section{Literature Review}

Most of the literature on the scholarship of librarians has been produced by U.S. researchers. Joswick studied journal articles published by 1,294 Illinois college and university librarians between 1995 and 1999 (340-49). Weller, Hurd, and Wiberly studied the contribution to peer-reviewed literature by practicing academic librarians in the U.S. from 1993-1997(352-62). In 2006 Wiberly, Hurd, and Weller updated their 1999 study to cover the period from 1998-2002, and also discussed patterns of co-authorship and identified institutional leaders in refereed publications (205-16). Crawford examined the nature of articles published in C\&RL and JAL in 1996 and 1997 (224-30). Bao analyzed the content of 682 refereed articles in C\&RL and JAL from 1990-1999 in relation to the 1992 ACRL Research Agenda (536-44). In 1997 Floyd and Phillips studied the question of whether pressures felt by librarians to publish within the constraints imposed by their institutions are affecting the quality of the library literature (81-93). In 1999 Mitchell and Reichel investigated the influence of scholarly requirements on librarians' ability to earn tenure (232-43). Kingma and McCombs looked at the opportunity cost of faculty status for librarians in an article published in 1995 (258-64). In 2001 Brown analyzed data on academic librarians' allocation of time for research contained in four studies conducted during the 1980's and1990's (59-70).

A Canadian study by Koufogiannakis, Slater, and Crumley published in 2004 reported a content analysis of librarianship research based on 2,664 articles contained in 91 LIS journals published in 2001 (227-39). 


\section{Methodology}

The scholarship survey was distributed to all identifiable university librarians employed by the Canadian Association of Research Libraries (CARL) ${ }^{2}$ during the spring and fall of 2006. The 39 question Web-based survey was available in English $^{3}$ and French ${ }^{4}$ versions, and potential respondents were invited to respond in their language of preference. In 2004/2005 there were 1,284 librarians employed at the 27 CARL universities (CARL Statistics 2004-2005 29). The survey population for the study consisted of the 1,052 CARL university librarians for whom functional email addresses could be retrieved. The survey attracted a total of 520 returns for a response rate of $49 \% .^{5}$ Four hundred forty-one responses (85\%) were in English; the remainder (15\%) were in French. Fifty-three of the survey returns were found to be seriously incomplete, and were removed from the sample. Another 44 respondents completed 26 of the 39 questions. An independent samples t-test of statistical variance found no significant difference between these 44 cases and the fully completed returns when compared with respect to age, gender, years of professional experience, and educational qualifications. Given this result, and the fact that these respondents had completed two-thirds of the survey questions, these cases were retained in the sample.

The adjusted sample upon which the following analysis is based consisted of 467 cases. This represents $44 \%$ of the survey population of 1,052 and $36 \%$ of the total population of CARL university librarians. A sample this size is considered to be statistically accurate within plus or minus 3 percent 95 percent of the time.

\section{Limitations of the Study}

There are 44 publicly funded universities in Canada. Due to limits of time and resources this study was confined to librarians from the 27 CARL universities. Although an initial attempt was made to expand the scope of the survey to include all university librarians in Canada, the response rate from the non-CARL libraries was so small as to be unusable. The exclusion of the "primarily

\footnotetext{
${ }^{2}$ The membership of CARL consists of the 27 largest university libraries in Canada plus the Canada Institute for Scientific and Technical Information (CISTI), Library and Archives Canada (LAC) and the Library of Parliament. This article will consider only librarians at the university members of CARL, which include the following universities: Alberta, British Columbia, Calgary, Carleton, Concordia, Dalhousie, Guelph, Laval, Manitoba, McGill, McMaster, Memorial, Montréal, New Brunswick, Ottawa, Québec à Montréal, Queen's, Regina, Saskatchewan, Sherbrooke, Simon Fraser, Toronto, Victoria, Waterloo, Western Ontario, Windsor, and York.

${ }^{3}$ English questionnaire: http://library2.usask.ca/ fox/scholarship/results/SurveySummaryEng2.asp

${ }^{4}$ French questionnaire: http://library2.usask.ca/ fox/scholarship/results/SurveySummaryFr4.asp

${ }^{5}$ Percentages used in this paper have been rounded to the nearest whole number to simplify the presentation of data.
} 
undergraduate" universities from the study is not to suggest that librarians at those universities do not participate in scholarly activities. In fact there are wellknown examples of librarians at these institutions who make significant contributions to the profession as writers and conference presenters. It is hoped that another researcher may be interested in conducting a comparative survey of the scholarship of the primarily undergraduate university librarians.

The survey data is based on a "self-selected sample". Librarians who responded to the survey were likely to be those who were interested in the subject. As such there is some possibility of over-representation in the sample by librarians who are active in scholarship.

The survey sample was over-represented by librarians in the early stages of their careers. Thirty-six percent of the initial sample was comprised of librarians with less than 7 years of professional experience, although this group makes up only $21 \%$ of the overall CARL librarian population (CARL Statistics 2005-2006 60-61). It is unknown to what extent this age distortion may impact the findings of this paper. However, the strong response to the survey from new librarians is gratifying, and indicates their degree of interest in issues related to scholarship, tenure and professional status. Differences in attitudes towards scholarship, and participation rates in scholarly activities by librarians at different ages and career stages, are topics for further study.

The gender profile of the sample matches the overall CARL librarian population almost perfectly, and there was a good distribution of responses by university, province and language group. Additional returns were solicited from librarians at the French-speaking universities of Quebec, who were substantially underrepresented in the initial results. Despite the stated limitations the author believes that readers can have some confidence in the conclusions of this report.

\section{The Distribution of CARL Librarians}

The CARL university libraries vary considerably in size. The number of librarians per university ranges from 19 for the University of Regina to 169 for the University of Toronto, with a median of 41 (CARL Statistics 2004-2005 29).

\section{Definition of Scholarship and Related Terms}

The definition of scholarship proposed in the survey was developed at Oregon State University and described by Weiser in 1996. Building on the work of Ernest Boyer (1-147), OSU defined scholarship in broad terms as any form of creative intellectual work validated by peers and communicated (Weiser). However, in the collection of data, in order not to limit results, survey respondents were asked to 
rank and to report their participation in eighteen activities that might be considered to be scholarship, whether or not these activities were formally peer reviewed. ${ }^{6}$ It is significant that most of the activities ranked highest by participants do include some form of peer or editorial review, and therefore the ranking conforms closely to the proposed definition of scholarship.

The communication of scholarly work may take place in a variety of forms, including published books and articles, public lectures and conference presentations, poster sessions, curated exhibits, artistic performances, etc. Course work towards advanced degrees does not meet the formal definition of scholarship, although a thesis or dissertation does.

In the counting of scholarly contributions no distinction was made in the survey between scholarship in the discipline of librarianship versus any other academic subject. In fact, survey participants reported a wide range of scholarly interests.

Sabbatical leave was defined in the survey as "leave to conduct a specific preapproved research project with the expectation of a publication or other research outcome." Study leave was defined as "leave for the purpose of taking a course, upgrading qualifications, etc." Annual research leave was defined as "a specific number of days per year of paid leave for general self-directed research."

\section{Survey Participants}

Ninety-nine percent of survey respondents possessed an MLIS degree or its historical antecedent. However, in the participant sample there were a small number of individuals without an MLIS or equivalent, but who had other advanced degrees, who were performing work of, or similar to, a librarian, who were eligible for tenure, and whose responses to the survey questions were consistent with others in the sample. These respondents were considered to be "equivalent to a librarian" and are included in the survey results. ${ }^{7}$

\section{The Motivation for Scholarship}

What motivates librarians to engage in scholarship activities? Survey participants were asked to rank a list of potential outcomes of scholarship in order of importance to them. Figure 1 shows the results of that ranking.

\footnotetext{
${ }^{6}$ See Figures 5, 12.

${ }^{7}$ Several of these individuals were archivists. In the CARL universities archivists often report to the Director of Libraries, and are governed by the same collective agreements and conditions for promotion and tenure as librarians.
} 


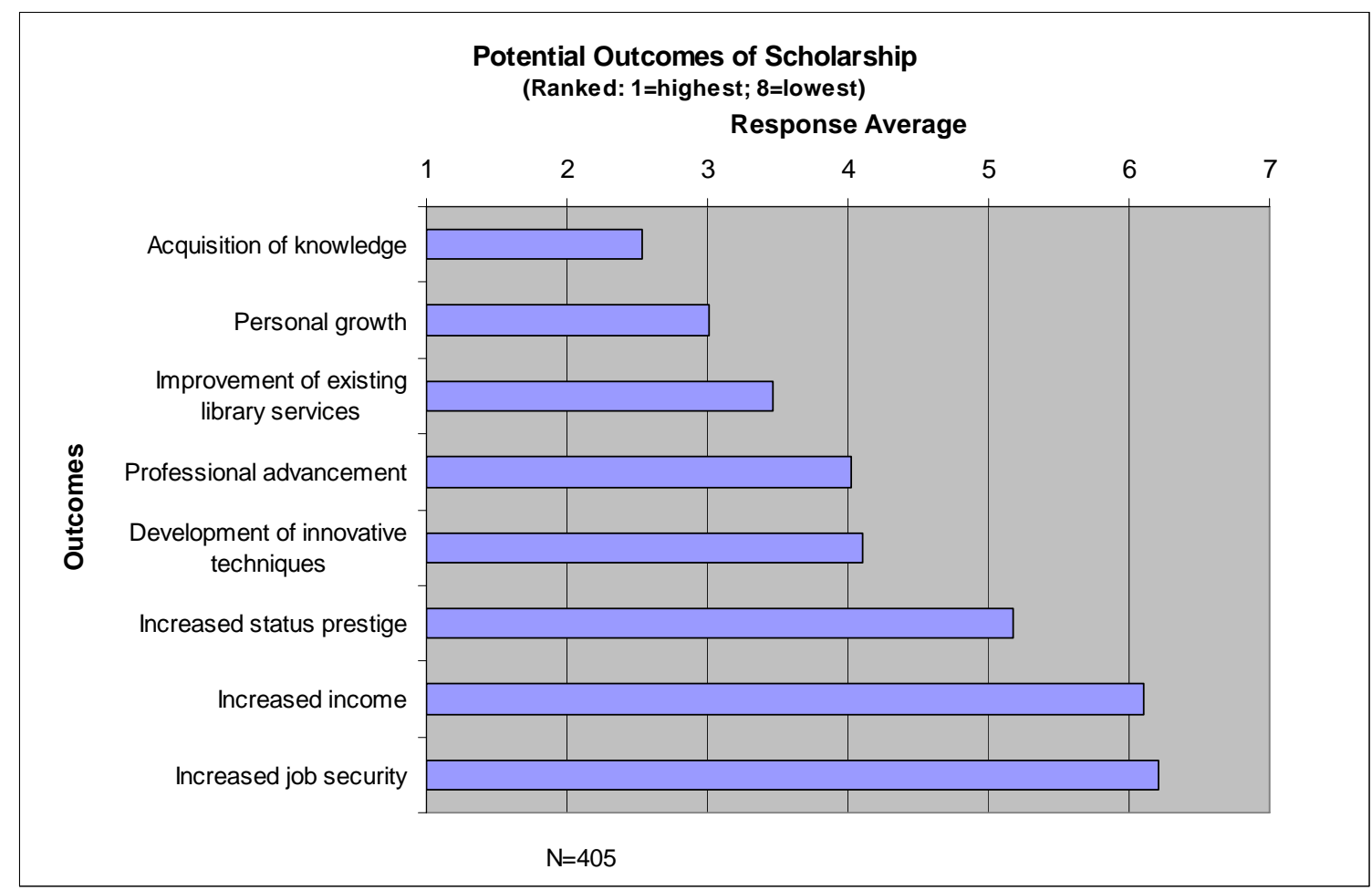

Figure 1: Potential Outcomes of Scholarship

Interestingly, the top ranking motivators were related to professional development and improvement of library services rather than increased income or job security. Despite the fact that scholarship activity is often a requirement for tenure and promotion in universities, it appears that librarians' primary purpose for engaging in scholarship is to learn and grow as professionals. Another altruistic motivation was expressed by one participant in the following statement:

"None of the options given for the outcomes of scholarship reflected why I engage in it. I do it to contribute to the world of knowledge. At my stage of career there are no financial or reputational things to be gained. My research is in an academic discipline and not in librarianship so my contributions to the profession are minimal."

\section{The Requirement for Scholarship}

Figure 2 shows that more than half (51\%) of survey respondents indicated that scholarship is either required or encouraged at their university. Scholarship is 
naturally expected during sabbatical and study leaves, where available, but for $35 \%$ of participants scholarship was also expected as an integral part of their professional responsibilities on an ongoing basis.

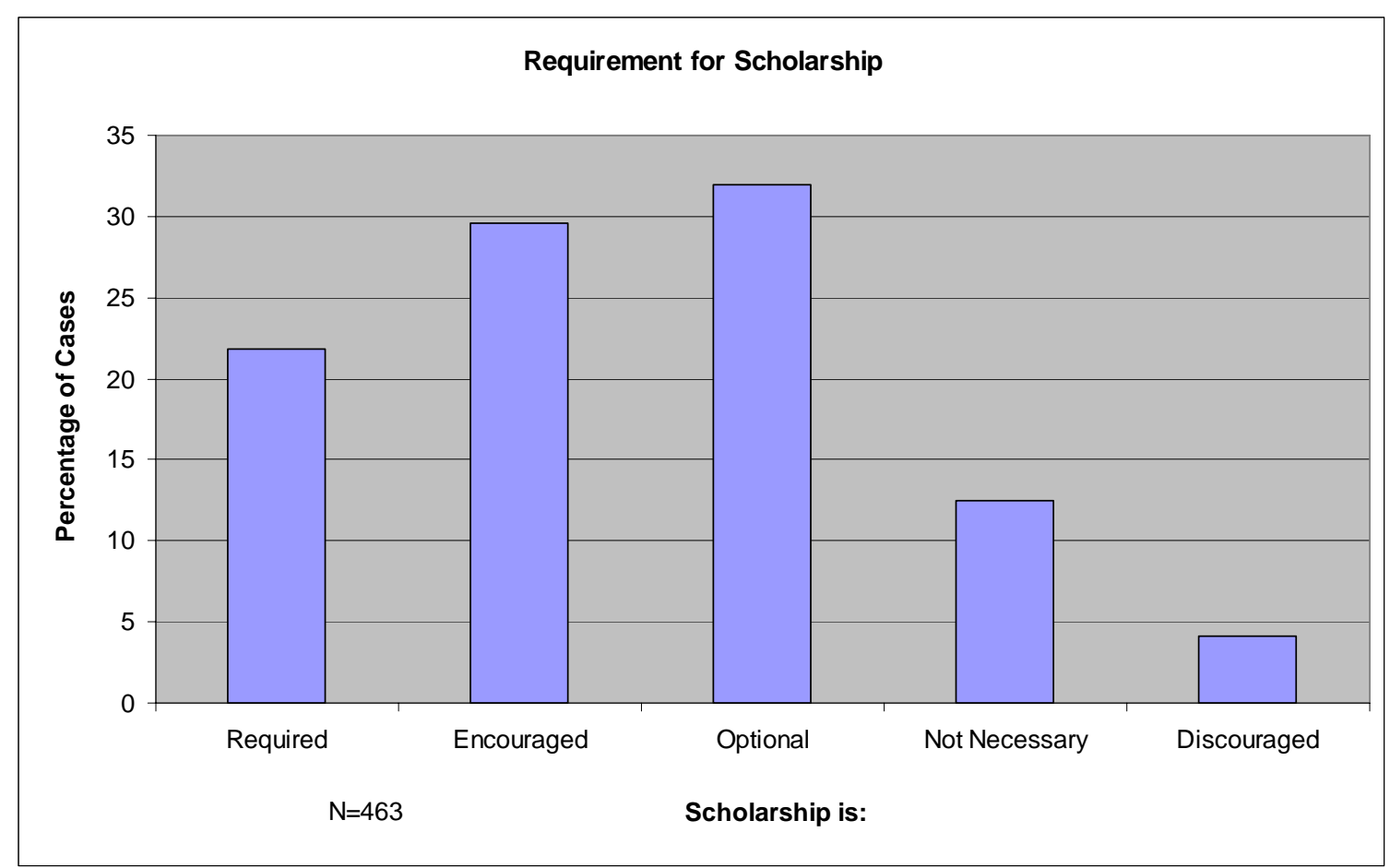

Figure 2: Requirement for Scholarship

In written comments several participants expressed frustration that although there is an expectation for scholarly work in order to secure tenure and promotion, their burden of assigned duties leaves little time or energy for this purpose. Furthermore, as Table 1 demonstrates, most universities have not provided their librarians with either formal or informal guidelines concerning an appropriate time commitment to scholarship.

\section{Table 1: Guideline for Scholarship Time Commitment}

Q18: Does your university have an accepted guideline for the percentage of time librarians should devote to scholarship?

\begin{tabular}{|l|r|r|}
\hline Response & Frequency & Percent \\
\hline Yes & 53 & 11 \\
\hline No & 334 & 72 \\
\hline Don't Know & 76 & 16 \\
\hline Total Respondents & 463 & 100 \\
\hline
\end{tabular}

Of the survey participants who indicated that their university did provide a scholarship time commitment guideline, only $61 \%$ indicated that this guideline 
was a formal policy or standard, and only $62 \%$ indicated that the guideline applied to all librarians.

Figure 3 shows the distribution of responses to the question on recommended scholarship time commitment. While the most common response was $10-14 \%$, answers ranged from less than $5 \%$ to over $40 \%$.

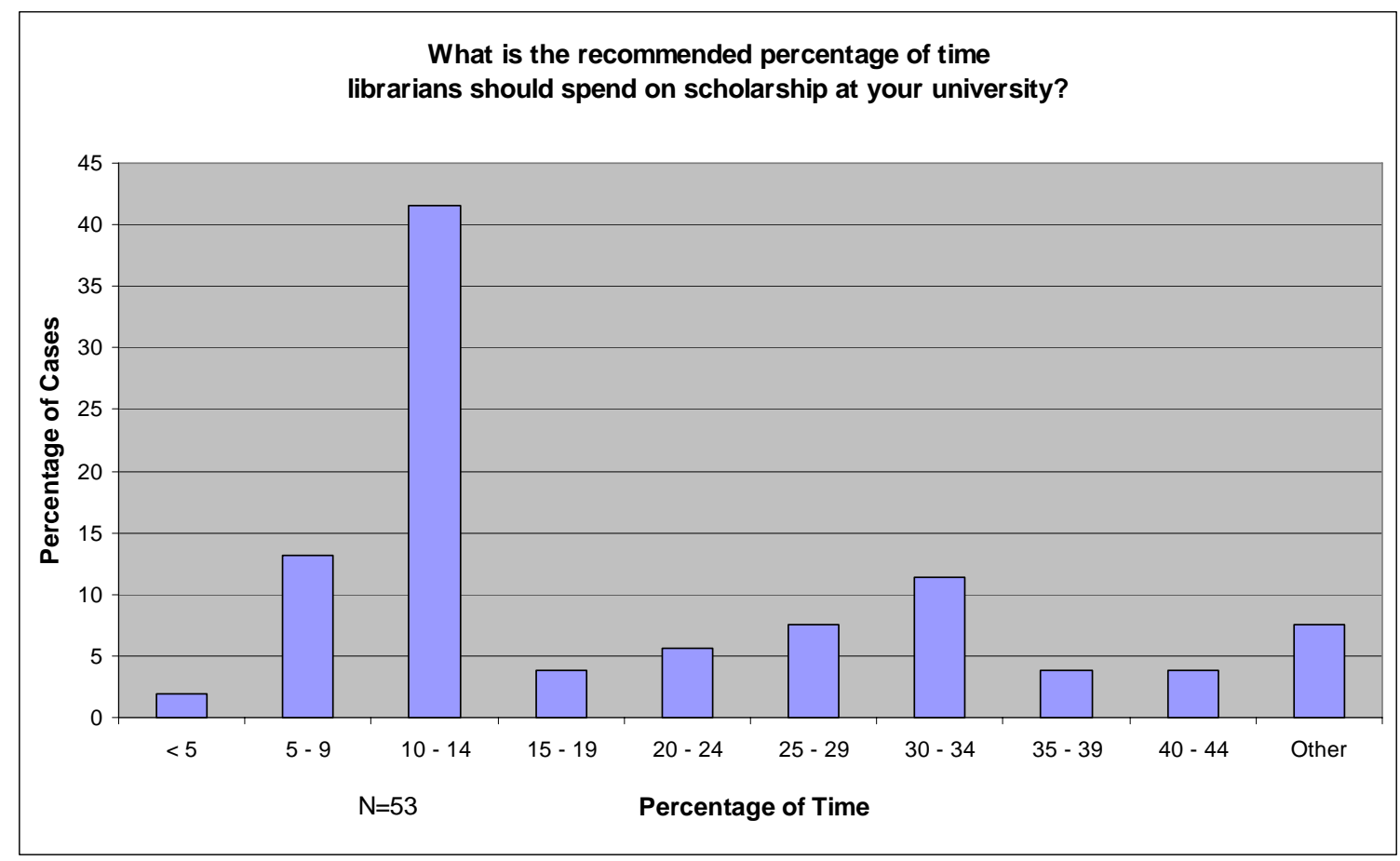

Figure 3: Recommended Scholarship Time Commitment

\section{Tenure and Promotion}

Evidence of scholarship is often a requirement for tenure and promotion of university librarians. Eighty-one percent of survey participants indicated that they were eligible for tenure, or its equivalent, at their institution. ${ }^{8}$ However, when asked to rank the relative importance of scholarship against other factors required for tenure and promotion, survey participants ranked scholarship lower than professional practice and contributions to the library, and slightly lower than contributions to the profession and the university (Figure 4).

The four French-speaking universities of Quebec represent an interesting side study. Currently, librarians at these universities do not experience the same level of academic benefits and obligations as research university librarians elsewhere in Canada. At these four universities librarians are not eligible for tenure or sabbatical leave, and the expectations for scholarship are lower. The

\footnotetext{
${ }^{8}$ Fourteen percent responded that they were not eligible, and the remaining five percent answered "Don't Know".
} 
francophone librarians of Quebec spend approximately 5\% more of their time on professional responsibilities and $5 \%$ less time on scholarship than the survey sample as a whole.

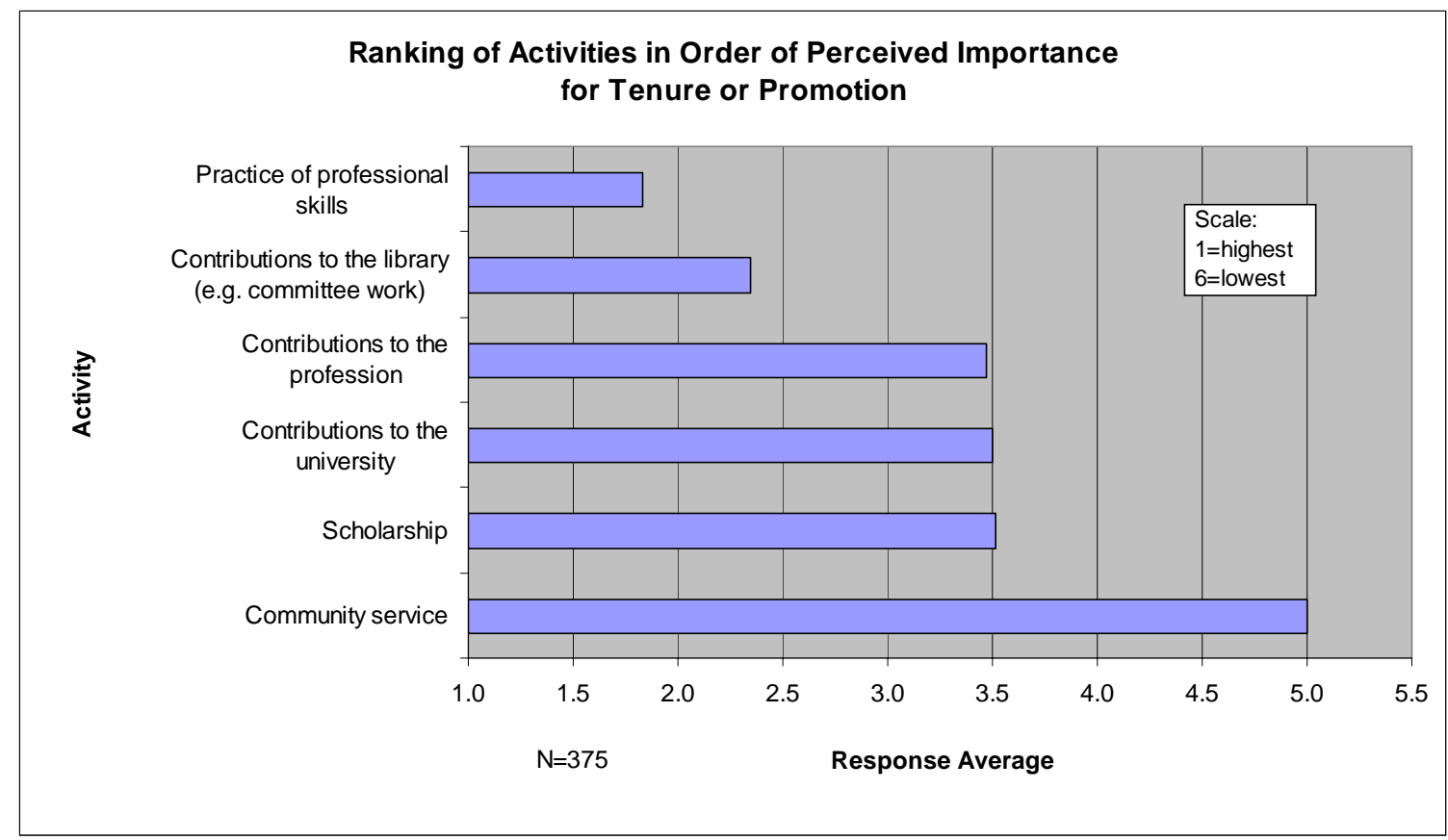

Figure 4: Ranking of Activities for Tenure or Promotion

Survey participants were asked to rank eighteen forms of scholarly expression on a scale of 1 to 5 in terms of their perceived importance towards achieving tenure and promotion. Figure 5 shows the results of that question in ranked order. In general, participants ranked formal publications higher than conference presentations, and conference presentations higher than poster presentations or informal activities such as blogs, websites and unpublished reports. For example, on the 1 to 5 scale the rating of 4.06 for "Articles in Peer-Reviewed Journals" implies that peer-reviewed articles are considered a more important form of scholarship than "Published Book Reviews" with a rating of only 2.83 . International presentations were seen as more important than national or provincial and regional presentations.

Additional activities mentioned in written responses to this question included bibliography, software development, translation of professional books, teaching, and digital project development. Some participants listed serving on the executive of national committees, and workshop and conference planning as contributions to scholarship. While these activities may indeed promote the scholarship of others, they are normally considered to be contributions to the profession rather than scholarship. 


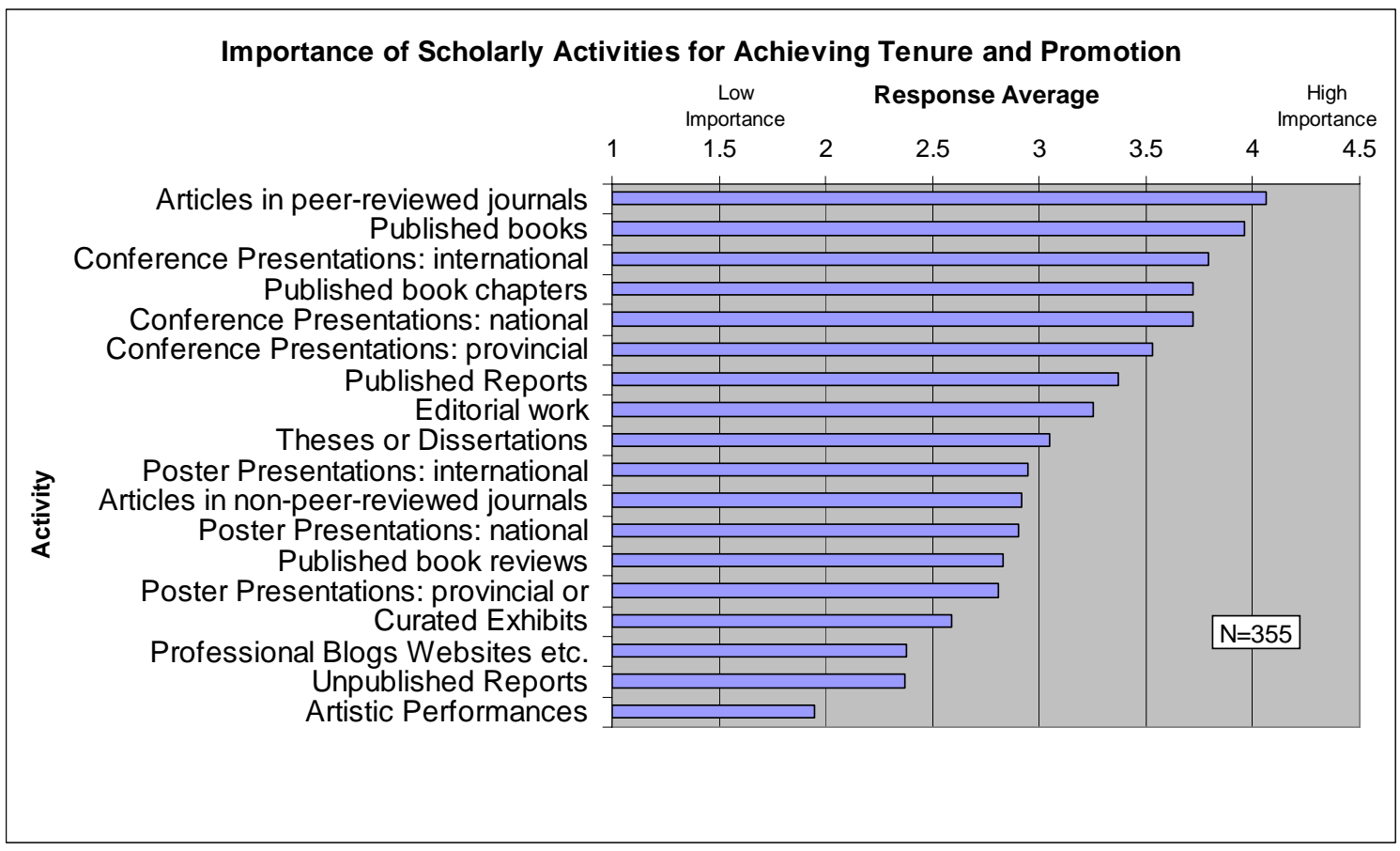

Figure 5: Importance of Scholarly Activities for Tenure and Promotion

\section{Support for Scholarship}

Seventy-five percent of survey participants reported that librarians at their university were eligible for sabbatical leave. Seventy-three percent were eligible for study leave, and 31\% for annual research leave.

Figure 6 shows the results of questions concerning librarians' eligibility for funding to support scholarship. Whereas more than $70 \%$ of librarians receive an annual professional allowance which may be used to support scholarly activities, only half of survey participants indicated that they were eligible for specially designated research funding. A disturbingly high percentage of participants answered "Don't Know" to these questions. 


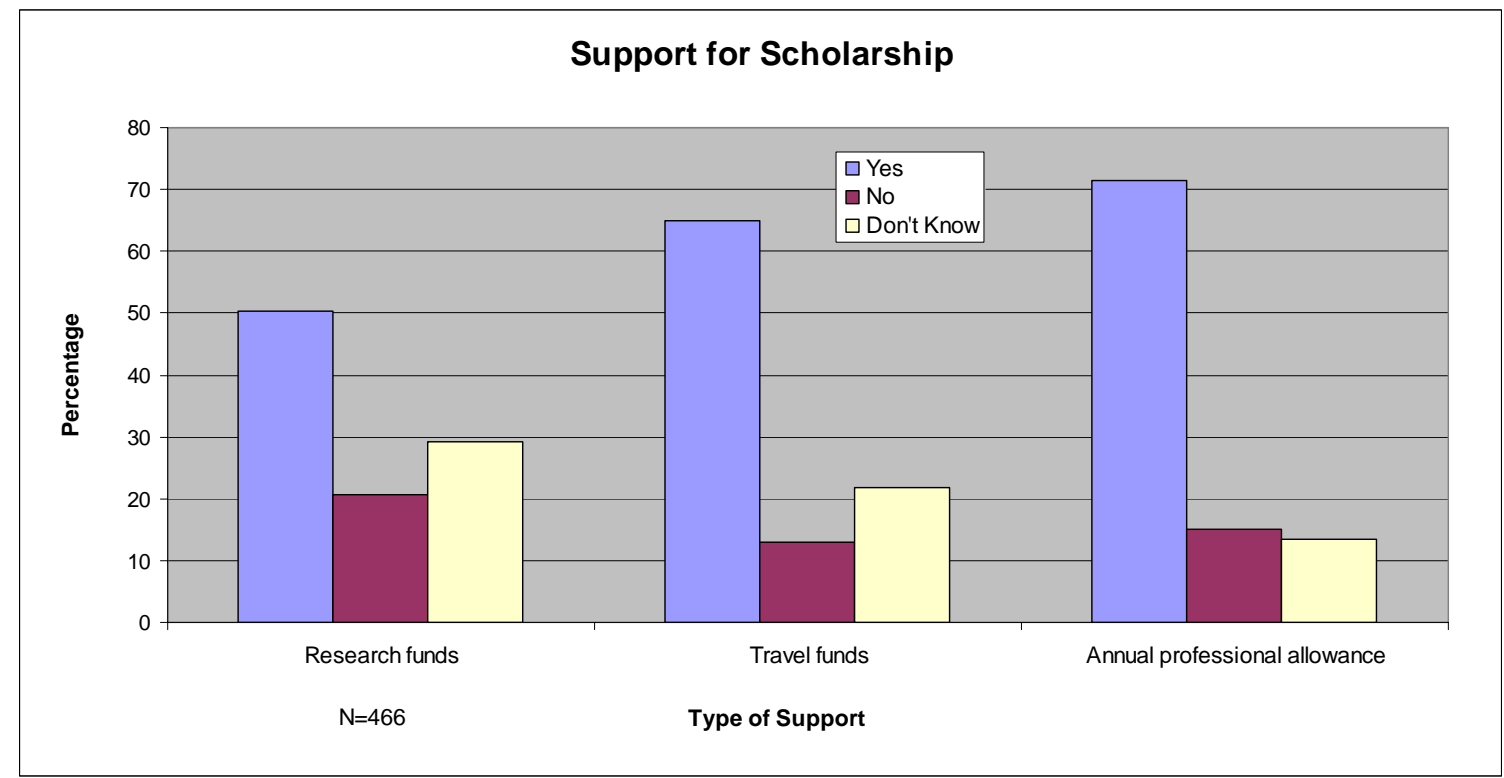

\section{Figure 6: Support for Scholarship}

When asked to rate the level of various types of support for scholarship, only $22 \%$ of participants rated research funding as Good to Excellent. Only 28\% rated provision of time for scholarship as part of regular ongoing duties as Good to Excellent. By comparison more than half of participants were satisfied with the conditions for sabbatical leave and $44 \%$ were content with arrangements for study leave (Figure 7).

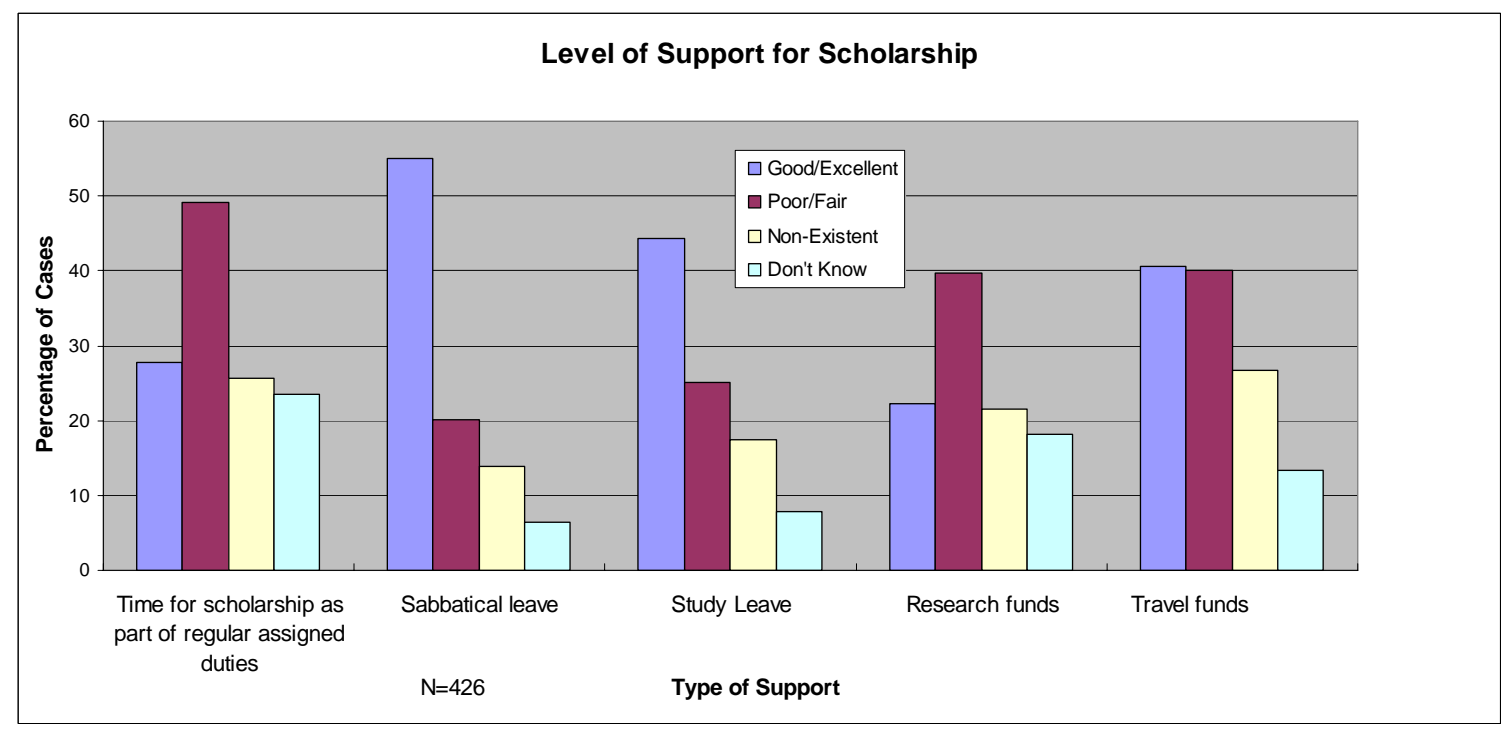

Figure 7: Level of Support for Scholarship 


\section{Participation in Leaves}

Leaves of absence can be an important factor in promoting research productivity. However, less than a quarter of the librarians surveyed had participated in any particular type of leave. For example, only $21 \%$ of the overall sample had taken a sabbatical leave. However, since not all universities provide all types of leave, it is probably more instructive to look at percentage participation by those librarians who are eligible for leave. Figure 8 shows participation in leaves for the purpose of completing scholarship with the "Not Applicable" responses removed.

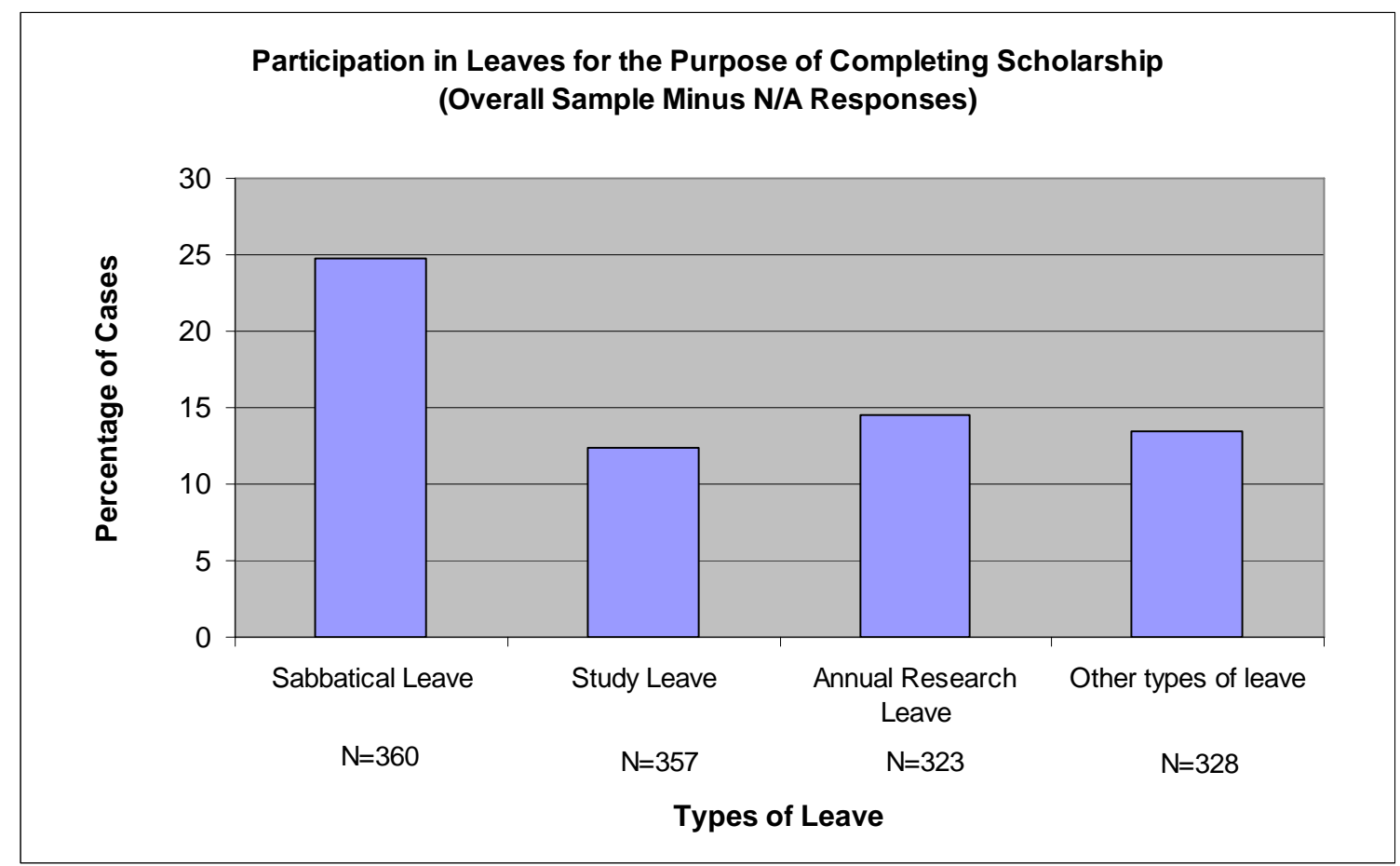

Figure 8: Participation in Leaves

Figure 9 shows the distribution of leaves for those survey participants who had taken them. Not surprisingly, in most cases the most common response is one leave taken. The exception occurs for Annual Research Leave. Some librarians are clearly taking advantage of this benefit where it is available. Seventeen survey participants reported taking more than 5 annual research leaves. 


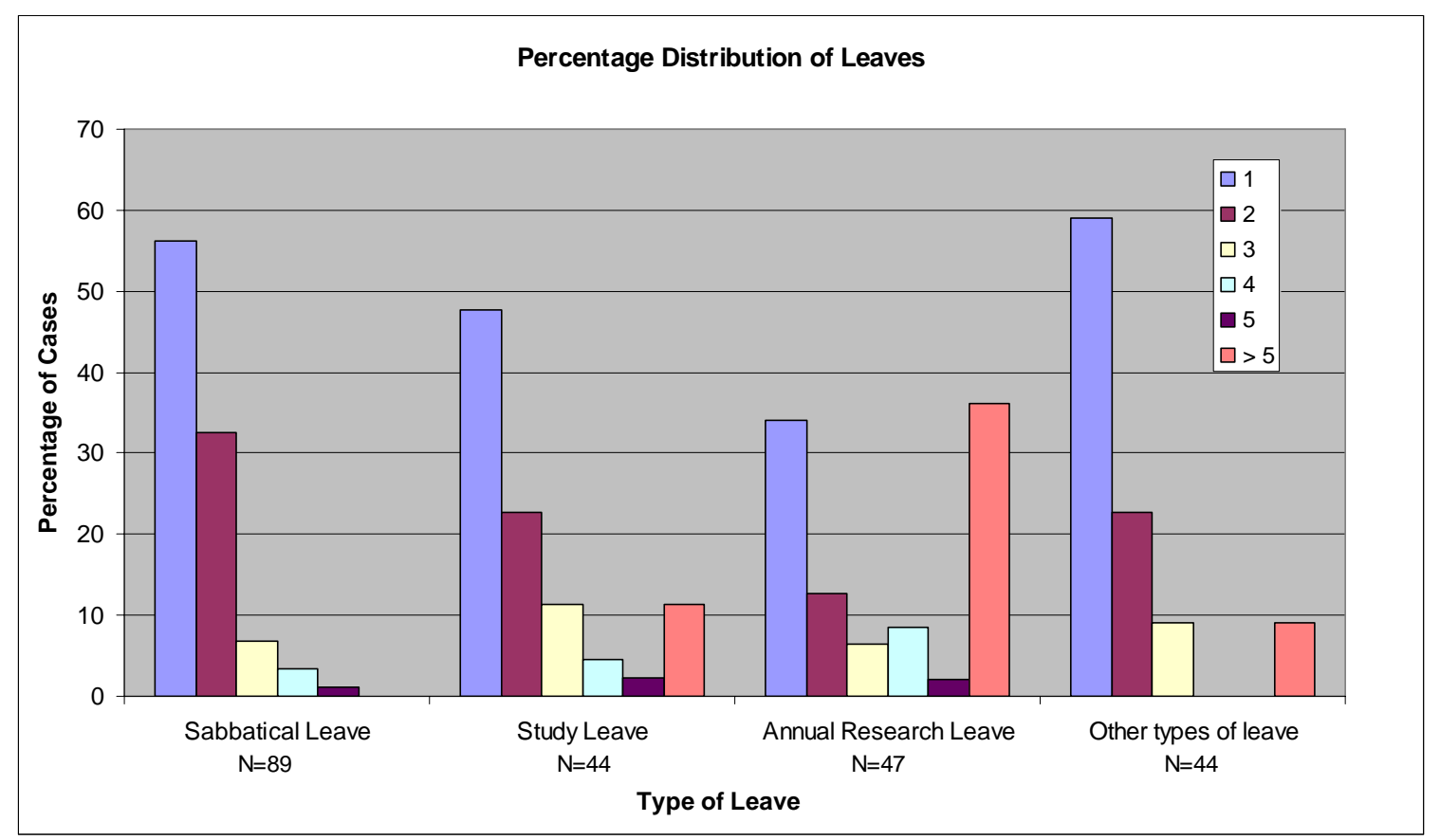

Figure 9: Percentage Distribution of Leaves

Considering the low overall participation rate in leaves of absence, it is not surprising that librarians reported that most of their scholarly activity is completed during regular ongoing assigned duties. Figures 10 and 11 compare the percentage of scholarship completed during leaves versus the percentage of scholarship completed during regular ongoing duties. One third of survey participants who had taken leaves reported that no more than $10 \%$ of their scholarly activities were completed during leaves. On the other hand, over a quarter of survey participants indicated that over $90 \%$ of their scholarly activity is completed during regular ongoing duties. Interestingly, an almost equal percentage indicated that $10 \%$ or less of their scholarly activity is completed without leaves of absence. 


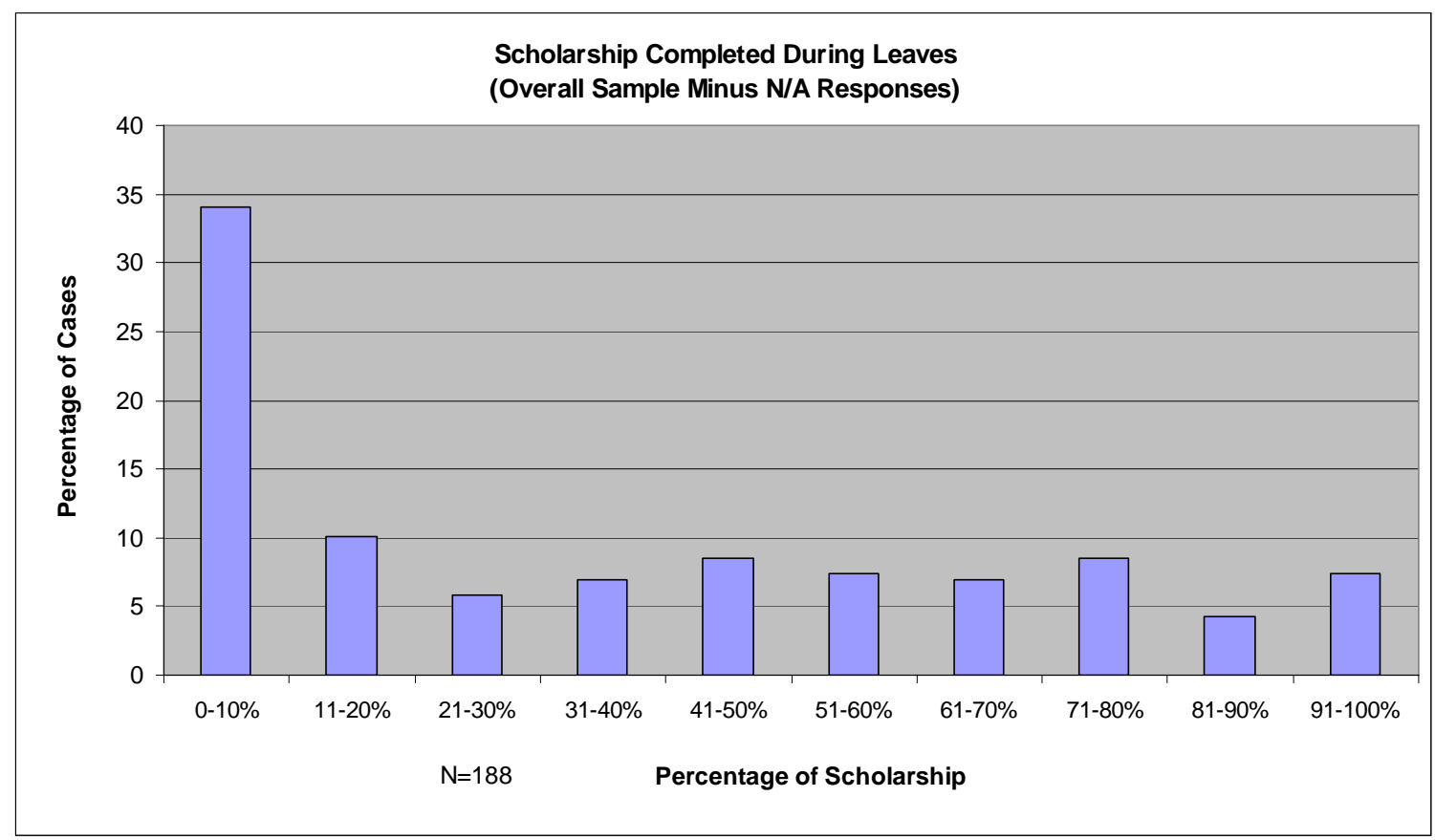

Figure 10: Scholarship Completed During Leaves

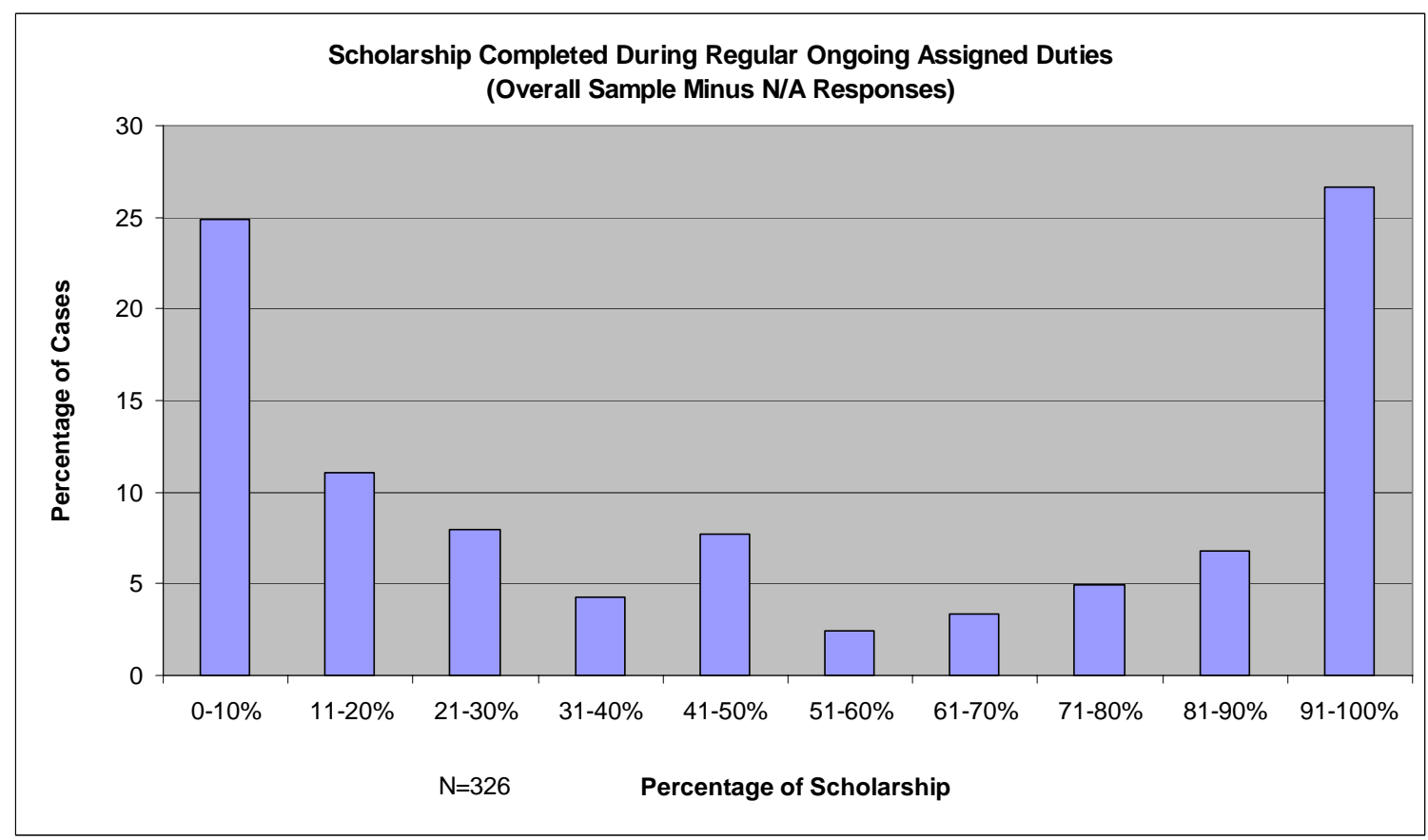

Figure 11: Scholarship Completed During Regular Assigned Duties 


\section{Participation in Scholarly Activities}

Figure 12 shows the participation rate by survey respondents in eighteen forms of scholarly communication in ranked order. The most common form of scholarship, practiced by more than two thirds of survey participants, was provincial and regional conference presentations.

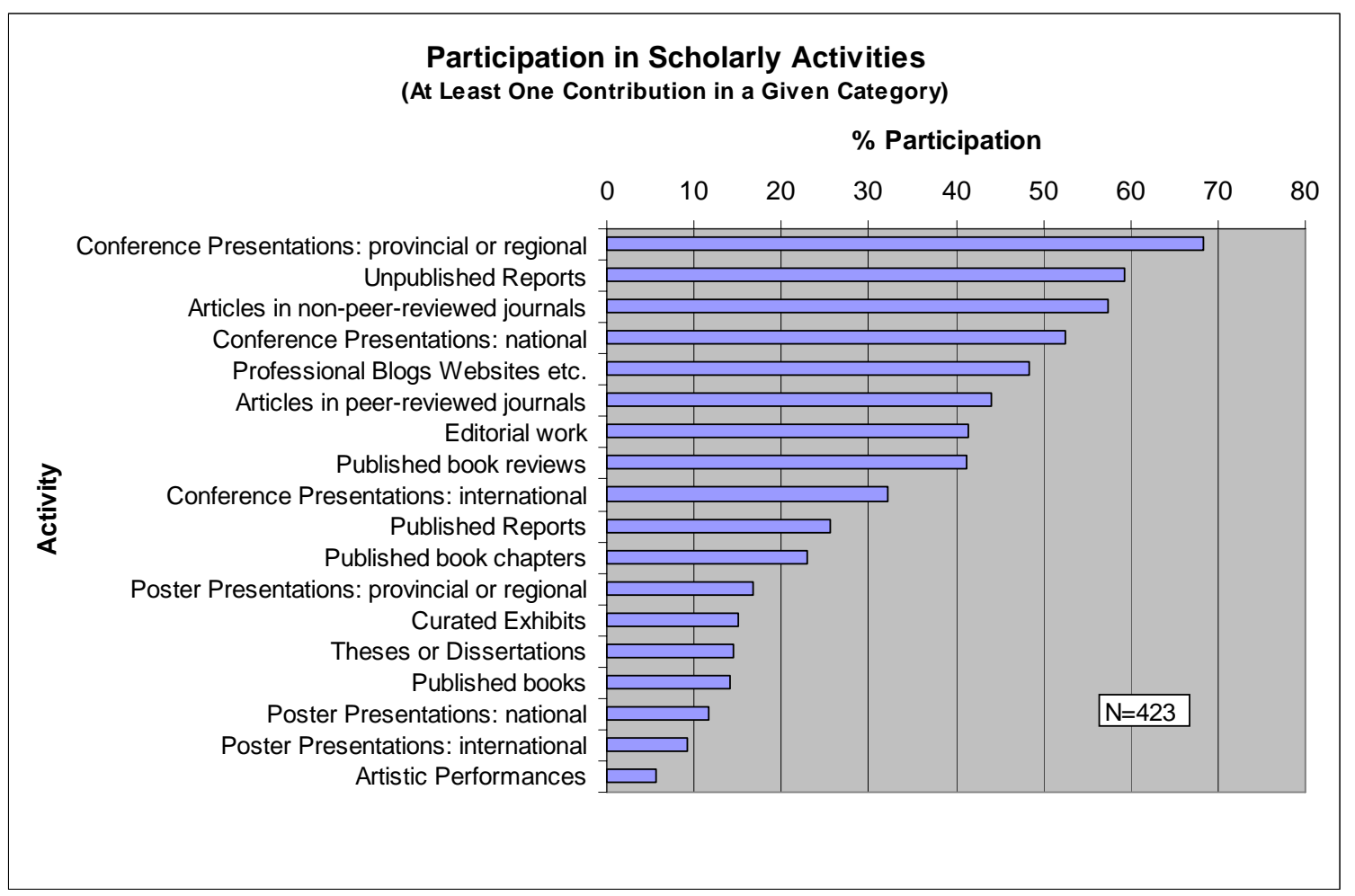

Figure 12: Participation in Scholarly Activities

The author was interested in exploring the distribution of individual scholarly activity by combining the frequency of contributions with the relative importance of those contributions for achieving tenure and promotion shown in Figure 5. The product of these two factors could be considered to be a measure of each individual's "scholarly intensity".

Since the data on the number of scholarly contributions was collected in ranges, for the purpose of computing scholarly intensity a score was assigned to each range according to the scale shown in Table 2. 
Table 2: Scholarly Contribution Score

\begin{tabular}{|l|c|}
\hline $\begin{array}{c}\text { Contribution } \\
\text { Range }\end{array}$ & $\begin{array}{c}\text { Contribution } \\
\text { Score }\end{array}$ \\
\hline Zero & 0 \\
\hline $1-2$ & 1 \\
\hline $3-5$ & 2 \\
\hline $6-10$ & 3 \\
\hline $11-20$ & 4 \\
\hline More than 20 & 5 \\
\hline
\end{tabular}

A simple illustration of this methodology is shown in Table 3 . In this example an individual who had published 3-5 peer-reviewed articles would have a higher scholarly intensity score than one who had produced the same number of book reviews.

Table 3: Scholarly Intensity Score

\begin{tabular}{|c|l|c|c|c|c|}
\hline Individual & $\begin{array}{c}\text { Type of } \\
\text { Scholarship }\end{array}$ & $\begin{array}{c}\text { Contribution } \\
\text { Range }\end{array}$ & $\begin{array}{c}\text { Contribution } \\
\text { Score }\end{array}$ & $\begin{array}{c}\text { Importance } \\
\text { Factor }\end{array}$ & $\begin{array}{c}\text { Scholarly } \\
\text { Intensity } \\
\text { Score }\end{array}$ \\
\hline A & $\begin{array}{l}\text { Peer- } \\
\text { reviewed } \\
\text { article }\end{array}$ & $3-5$ & 2 & 4.06 & 8.12 \\
\hline B & $\begin{array}{l}\text { Book } \\
\text { Review }\end{array}$ & $3-5$ & 2 & 2.83 & 5.66 \\
\hline
\end{tabular}

Figure 13 shows the "Scholarly Intensity" distribution of individual participants in the survey. The levels of scholarly intensity (Low, Below Average, Above Average, High) are based on the mean and standard deviation in the data. The chart suggests that $13 \%$ of the survey participants are active scholars, $29 \%$ are above average, $46 \%$ are below average, and $11 \%$ exhibit low scholarly output. 


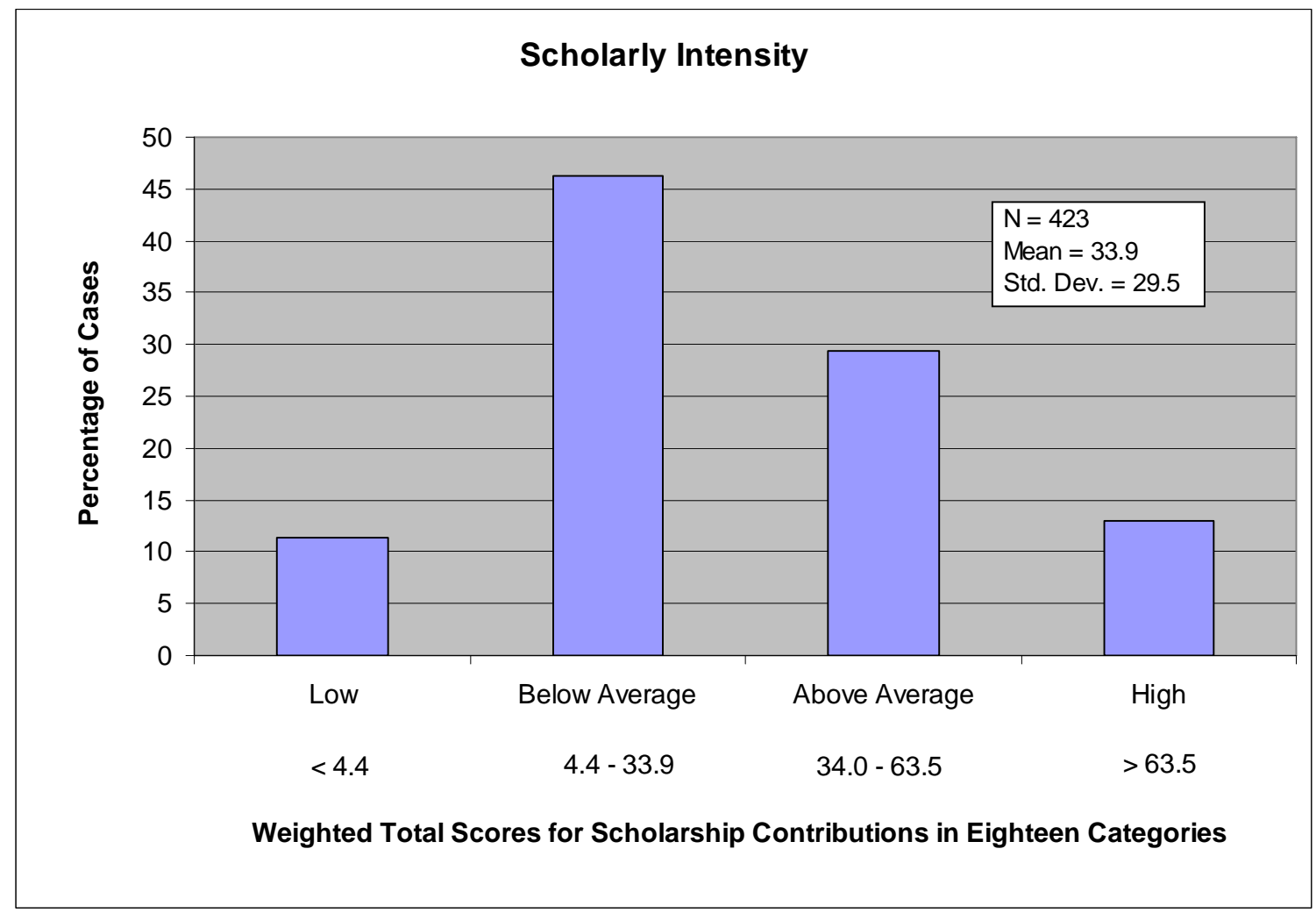

Figure 13: Scholarly Intensity

Figure 14 shows a cross-tabulation between level of scholarly intensity and gender. The data suggest a positive correlation between gender and scholarship. Male librarians are more likely to be represented in the Above Average and High categories of scholarly intensity and female librarians are more likely to be represented in the Below Average and Low categories. A Chi-square test of statistical significance indicated this result to be significant at the $99 \%$ level. The survey does not suggest any reason for this result, although there was also a statistically significant difference between male and female librarians in terms of hours per week devoted to scholarship. Male librarians were more likely to be in the Medium and High categories in terms of time devoted to scholarship, while female librarians were more likely to be in the Low category. 


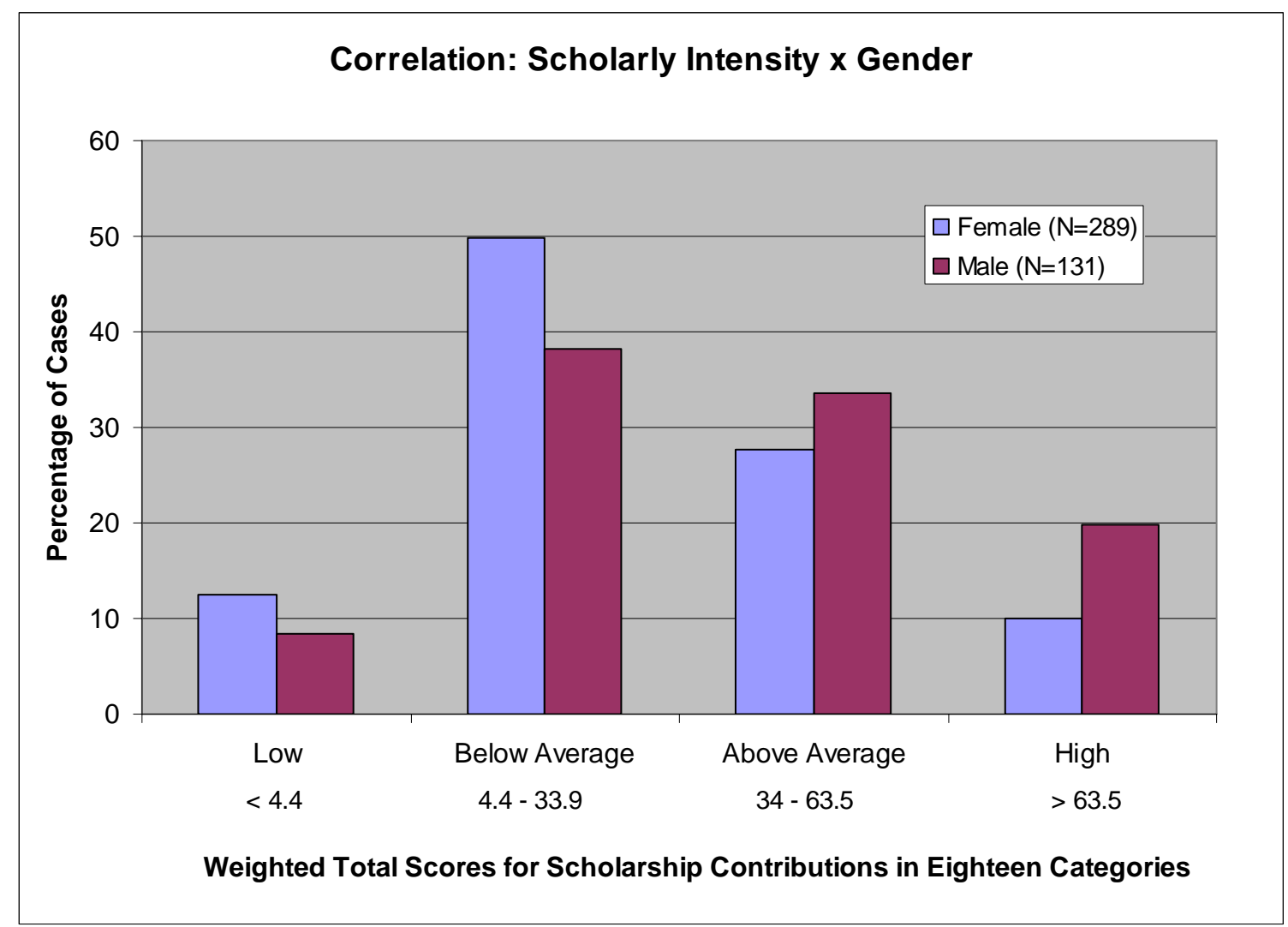

Figure 14: Scholarly Intensity x Gender

Survey participants were asked to indicate the subject areas of their scholarship from a pre-defined list. Multiple responses were possible. Figure 15 shows the results in ranked order. 


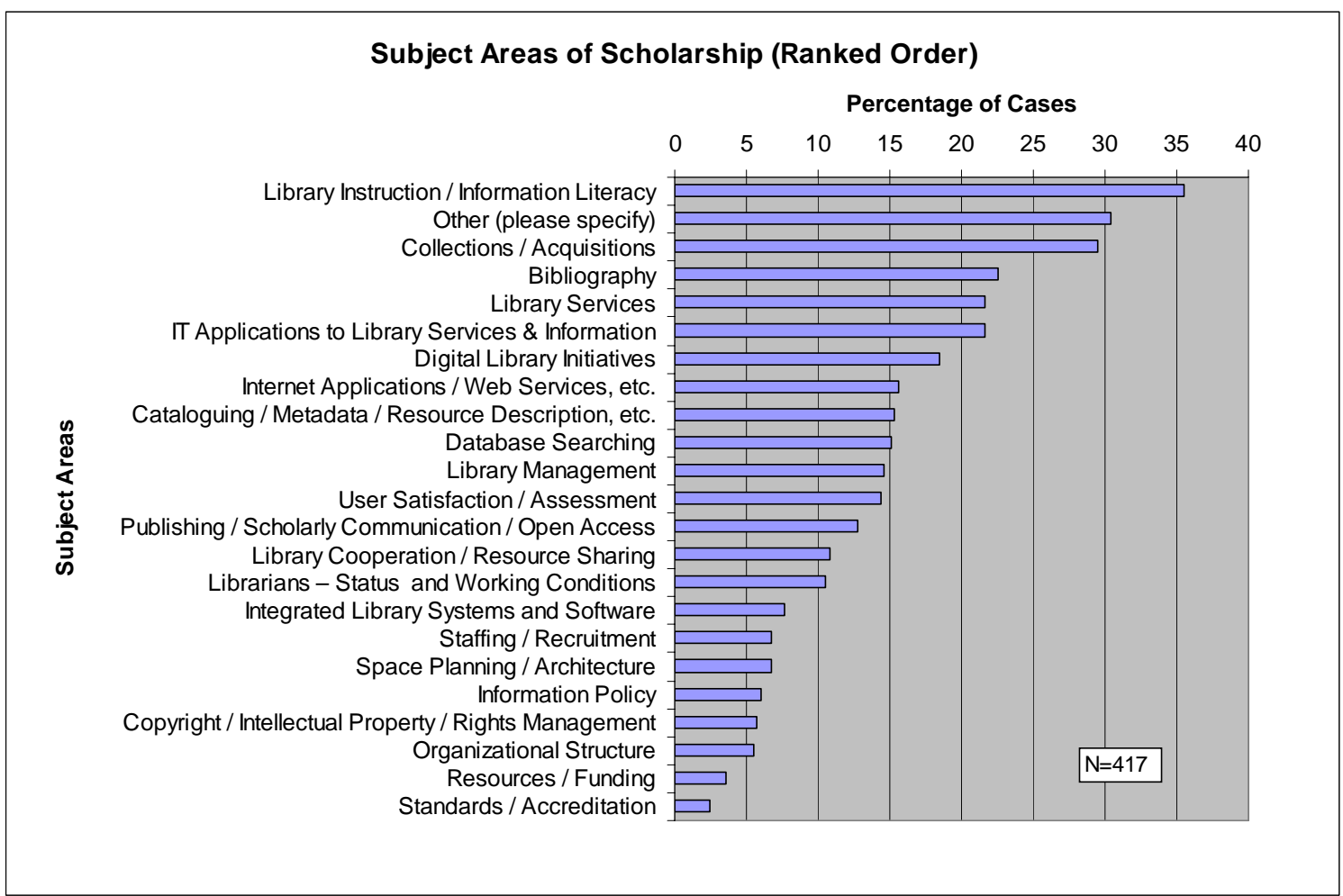

Figure 15: Subject Areas of Scholarship

Judging from the large percentage of "Other" responses the list of options was not extensive enough. A common criticism of the list was that it was too focused on librarians and the library profession, and did not include an option to indicate research interests in disciplines beyond the field of librarianship. Participants listed a diverse array of other academic interests including:

- Academic integrity and plagiarism

o Access to information and protection of privacy

o Arabic script paleography and codiology

o Architectural history

- Asian history

o Avant-garde film

- Canadian intellectual history

o Canadian music history

o Children's literature

o Consortia

- Cultural perceptions of librarians, libraries, print culture and the Internet

o Distance Education

o Diversity issues

o Educational Administration

o Educational theory and practice

o Evidence-based librarianship

o Evidence-based medicine

o Fine art o Information-seeking behavior

o International law and international legal bibliography

o International librarianship

o Jewish biblical interpretation

o Knowledge management

o Languages and translation

o Law and religion

o Library assessment

o Library history

o Literacy, teaching and learning

o Liturgical objects related to art history

o Marketing

o Musicology

o Naval history

o Nineteenth Century British literature

o Philosophy and history of medicine

o Print culture studies

o Rare books

- Russian language and culture

o Semiotics 


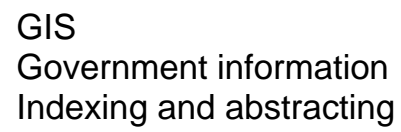

o Web 2.0 applications

\section{Summary and Discussion}

More than half the participants in a survey of Canadian research university librarians are either required or encouraged by their universities to participate in scholarly activities. However, librarians claim that their engagement in scholarship is motivated primarily by a desire for professional growth and selfimprovement rather than reasons related to increased income or job security.

Librarians who are eligible for tenure and promotion indicated that scholarship is less important for attaining these benefits than accomplishments in the areas of professional practice and contributions to the library. Librarians ranked formal publications to be the most important expression of scholarship for obtaining tenure and promotion, followed by conference presentations, followed by poster presentations. A number of alternative forms of scholarship were reported.

Support for scholarship is extremely variable. Considering the overall sample, the majority of librarians were satisfied with leave benefits, but few were satisfied with specific funding for research and time available for scholarship during the course of their regular work.

Less than a quarter of survey participants had participated in any form of leave of absence for the completion of scholarship, although three quarters indicated that librarians at their universities were eligible to take such leaves. Why should there be such a large discrepancy? Part of the explanation may be that $36 \%$ of the survey sample was comprised of librarians with less than 7 years of professional experience. At most universities sabbatical leave is restricted to librarians with tenure, and only after 6 or 7 years of service. Nevertheless the large gap between eligibility and participation in sabbatical leave is a concern. What are the impediments to greater participation in sabbatical leave? Are there financial obstacles? Are there other factors discouraging librarians from applying for leave? Are there age or gender differences related to sabbatical participation? Further research needs to be conducted to answer these questions.

The data suggest that librarians generate most of their scholarly activity without the benefit of leaves of absence.

Librarians pursue a rich array of scholarly interests that extend well beyond the everyday issues of professional practice. Thirteen percent of the survey sample could be considered active scholars and $11 \%$ exhibited a low level of scholarly output. 
This study has suggested there may be a connection between level of "scholarly intensity" and gender. However, due to the manner in which the data were collected (i.e. the grouping of scholarly contributions in ranges rather than by exact count) this conclusion can only be tentative at this point. Further investigation requiring the collection and analysis of more precise data would be needed to confirm this result.

There is no evidence that female librarians are any less interested in scholarship, or less capable of producing scholarly work than their male counterparts. Since many survey participants commented that much of the time they devote to scholarship is "after hours" during their "own personal time", perhaps part of the explanation for the apparent gender gap in scholarship may be differing levels of competing demands on the personal time of male and female librarians. If this turns out to be the case, one approach to reducing the differential in scholarly activity may be to ensure that all librarians have adequate time for scholarship during the course of their "regular work week".

\section{Questions for Further Study}

What is the explanation for the stronger than expected response rate to the scholarship survey by librarians with less than seven years of professional practice? Does the level of interest by "new librarians" reflect a change in perspective in recent MLIS graduates? Could changes in external expectations or requirements for tenure be a factor? More generally, how have expectations for scholarship evolved over time, and what is the attitude towards scholarship, and the participation rate in scholarly activities, by librarians at different ages and stages in their careers?

What are the differences in scholarly expectations, levels of support, and scholarly output between Canadian and U.S. university librarians? Are there demographic or environmental factors that would lead to differences in scholarly output? For example, is there a difference in the proportion of tenure track librarians between the U.S. and Canada?

In consideration for tenure and promotion of librarians is scholarship in the field of librarianship given more weight than scholarship in other subject areas? Is theoretical scholarship given more value than applied scholarship?

A surprising finding of the scholarship study was the apparent uncertainty on the part of librarians at a few CARL universities concerning their eligibility for sabbatical leave, study leave, and tenure. It would be interesting to investigate why this is the case. Is this finding isolated to libraries where these benefits are not well established? Is there a lack of interest on the part of some librarians? 
If there is a "gender gap" in the scholarly output of librarians, what are the contributing factors? Are there other variables in addition to the availability of discretionary time for scholarship mentioned in the previous section? Are there different expectations for scholarship, either personal or institutional, for men and women? Is there any evidence of gender discrimination, however subtle or latent, in the opportunities for scholarship?

Finally, what difference does the scholarship of librarians make to library users? Are scholarly librarians, and libraries that support and encourage scholarship, more innovative? Is there a measurable relationship between the degree of scholarship undertaken at certain libraries and the quality of library service delivered?

All of these questions would be interesting topics for further study. 


\section{Works Cited}

Bao, Xue-Ming. "An Analysis of the Research Areas of the Articles Published in C\&RL and JAL between 1990 and 1999." College \& Research Libraries 61 (November 2000) : 536-44.

Boyer, Ernest L. Scholarship Reconsidered: Priorities of the Professoriate. Princeton, N.J.: Carnegie Foundation for the Advancement of Teaching, 1990.

Brown, Jeanne M. "Time and the Academic Librarian." portal: Libraries and the Academy 1 (January 2001) : 59-70.

Canadian Association of Research Libraries. CARL Statistics 2004-2005, Table VIII - Summary of library personnel, 29.

Canadian Association of Research Libraries. CARL Statistics, Section D: Salaries: 2005-2006. Table VI - Average and median salary per year of professional experience - Librarian positions only, 60-61.

Crawford, Gregory A. "The Research Literature of Academic Librarianship: A Comparison of College \& Research Libraries and Journal of Academic Librarianship." College \& Research Libraries 60 (May 1999) : 224-30.

Floyd, Barbara L. Floyd, and John C. Phillips. "A Question of Quality: How Authors and Editors Perceive Library_Literature." College \& Research Libraries 58 (Jan. 1997) : 81-93. 
Joswick, Kathleen E. "Article Publication Patterns of Academic Librarians: An Illinois Case Study." College \& Research Libraries 60 (July 1999) : 340-49.

Kingma, Bruce R., and Gillian M. McCombs. "The Opportunity Costs of Faculty Status for Academic Librarians." College \& Research Libraries 56 (May 1995) :258-64.

Koufogiannakis, Denise, Linda Slater, and Ellen Crumley. "A Content Analysis of Librarianship Research," Journal of Information Science 30 (June 2004) : 227-39.

Mitchell, W. Bede, and Mary Reichel. "Publish or Perish: A Dilemma for Academic Librarians?" College \& Research Libraries 60 (May 1999) : 23243.

Weiser, Conrad J. The Value System of a University - Rethinking Scholarship. March 7, 1996. 4 Dec. 2006. $<$ http://www.adec.edu/clemson/papers/weiser.html>.

Weller, Anne C., Julie M. Hurd, and Stephen E. Wiberley. "Publication Patterns of U.S. Academic Librarians from 1993 to 1997." College \& Research Libraries 60 (July 1999) : 352-62.

Wiberley, Stephen E., Julie M. Hurd, and Ann C. Weller. "Publication Patterns of 
Partnership: the Canadian Journal of Library and Information Practice and Research, vol. 2, no. 2 (2007)

U.S. Academic Librarians from 1998 to 2002." College \& Research

Libraries 67 (May 2006) : 205-16. 